\title{
Design and Application of a Digital System for Information Management and Synchronous Analysis in a Foundation Pit Group
}

\author{
Zheng-Liang Xu, ${ }^{1}$ Xiong Wang $\mathbb{D}^{2,3}$ Ming-Guang Li ${ }^{2},{ }^{2,3}$ Zhong-Jie Zhang, \\ Fan-Yun Zeng, ${ }^{4}$ and Jin-Jian Chen ${ }^{2,3}$ \\ ${ }^{1}$ Shanghai Urban Construction Design \& Research Institute (Group) Co., Ltd., Shanghai 200125, China \\ ${ }^{2}$ Department of Civil Engineering, Shanghai Jiao Tong University, Shanghai 200240, China \\ ${ }^{3}$ Shanghai Key Laboratory for Digital Maintenance of Buildings and Infrastructure, Shanghai 200240, China \\ ${ }^{4}$ Power China Zhongnan Engineering Corporation Limited, Changsha 410014, China
}

Correspondence should be addressed to Ming-Guang Li; lmg20066028@sjtu.edu.cn

Received 3 October 2020; Revised 19 December 2020; Accepted 28 December 2020; Published 8 January 2021

Academic Editor: Guoyang Fu

Copyright (c) 2021 Zheng-Liang Xu et al. This is an open access article distributed under the Creative Commons Attribution License, which permits unrestricted use, distribution, and reproduction in any medium, provided the original work is properly cited.

\begin{abstract}
When several adjacent foundation pits are excavated simultaneously and alternately, the foundation pit group has the interactions which will aggravate the excavation-induced adverse impact on surrounding environment. However, due to the massive construction information and monitoring data during excavation, the effect of interactions on performance of the foundation pits is hardly examined. In this study, a digital system is developed to manage the construction information and monitoring data of the foundation pit group. On the one hand, a visualization management system based on Autodesk Revit is developed to record information such as geometry information, excavation stages, and instrument layout. The complex construction information can be inquired dynamically. On the other hand, a dynamic and synchronous analysis system is developed based on SQL Server external database, Visio, and Excel software. The SQL Server software is capable to facilitate data classification and standardization management. The excavation process and monitoring data are fused through the secondary development of Visio and Excel software to help visualize, respectively. The developed system is applied to the foundation pit group of Shanghai World Expo Project. The lateral deflection of diaphragm walls is investigated and the rebound phenomenon of diaphragm wall is interpreted. It confirms that the developed system can improve the information management so that the deformation behavior of the foundation pit group can be analyzed efficiently.
\end{abstract}

\section{Introduction}

With the acceleration of urbanization, the underground space exploitation tends to be larger and more intensive. Consequently, a large number of deep excavations have been carried out in the last two decades. When several adjacent foundation pits are excavated simultaneously and alternately, called foundation pit group, these foundation pits have the interactions, which will aggravate the excavationinduced adverse impact on surrounding environment. The interaction is a crucial factor that causes abnormal performance and increases construction risks $[1,2]$. The traditional management system of foundation pit mainly included BIM-based information system and other digital technologies which can act as effective communication tools, visualization, and data analysis in an integrated environment. Li and Shu developed a web-based information system for information management, visualizing, and data analyzing for shield tunnel construction [3]. Akanmu et al. developed an automated site layout modeling system using a combination of autonomous technologies. The proposed system relied on a platform and computational algorithms for database establishment and data analysis [4]. Lee et al. proposed a construction information database system based on BIM technology to enable the comprehensive management of information during construction progress [5]. Rodrigues et al. introduced a comprehensive management system in which the case study was modelled in Autodesk 
Revit software and a support database was developed in Microsoft SQL Server, and a web application was developed to implement the depiction and consultation of 3D model, parametric data, and construction information [6]. Lee et al. proposed a risk management system to monitor and evaluate the risk based on optimized grey Verhulst model, BIM3DGIS framework, and risk monitoring. The system can demonstrate well performance and monitor risk variation of deep excavation effectively [7]. Traditional management system is incapable of analyzing the effect of interactions on performance during several excavations efficiently. Moreover, the stress and deformation analysis become extremely complex due to inefficient management of massive data. The main difference between the proposed system and traditional construction risk monitoring systems is listed in Table 1. Specially, as the interaction of adjacent excavation is more reflected in local time and space in the foundation pit group, the modeling of excavation condition must be refined to the scale of local block excavation. Therefore, the research target of the proposed system is the interaction analysis in local time and space due to superposition effect of multiple block and partition excavation. The comparison is made from four aspects of modeling object, research target, data management, and data analysis.

To ensure the safety excavation, an effective system is urgently needed to manage several excavations information and investigate and analyze the interactions dynamically and synchronously from the overall construction. In this paper, a functional integration system was developed to implement the recording, visualization, and data analysis of construction progress which was then applied to a case study. The methodology adopted to be applied to the case study follows the following steps:

(1) VSCM: the foundation pit group was modelled with the Autodesk Revit software. The three-dimensional display of excavation process was carried out against elapsed time with the measuring points and monitoring data stored and inquired dynamically.

(2) Data establishment: the SQL Server software was used to facilitate data classification and standardization management.

(3) Visual modeling: the excavation stages and monitoring data were managed through the secondary development of Visio and Excel software to carry out dynamic and synchronous analysis, respectively.

(4) Application and results analysis: an API was developed to support application and analysis.

The abovementioned steps are taken to achieve refined management of massive construction information and monitoring data. Consequently, the system is capable to investigate the abnormal performance of foundation pit.

\section{Literature Review}

Detailed construction and monitoring information are the basic conditions for analysis of performance characteristics and their interactions. Therefore, the information of excavation progress and instrumentation should be recorded carefully. Hashash et al. introduced self-learning in engineering simulations (SelfSim) as a numerical simulations method to integrate multisource information during excavations. The soil models can be used to record constitutive soil information, field measurements, and other construction information in excavation activities [8]. Su et al. proposed the use of three-dimensional laser scanning technology to accurately capture construction activities during urban excavation. [9]. Fekete et al. demonstrated the advantages of employing a static Lidar system for geotechnical and operational application as the excavation advances. The system can be used to record the construction characterization including location and orientation and extract monitoring data in excavation progress [10]. Kim et al. monitored the construction progress through image processing technology and proposed a 4D CAD model [11]. Omar and Nehdi made a comprehensive comparison of four common construction site information acquisition technologies in installation, automation level, applicability, and integration level, including enhanced IT technologies, geospatial technologies, imaging technologies, and augmented reality (AR) [12]. Kang et al. proposed a project schedule management system to monitor the current construction status and completion degree of related facilities by comparing the real photos [13]. Sang et al. developed a novel measuring device to automatically record images and determined the displacement deformation of soil by the planar digital image correlation (DIC) technique [14].

Many researches have studied the database storage and query system for monitoring data management. However, some of the systems only forecast and analyze from statistical perspective of monitoring data, but are incapable to analyze with the excavation information. Kim et al. incorporated an artificial neural network (ANN) with monitored field data to predict deformation, and a standard format for a database of monitored field data is firstly proposed for sorting out massive monitoring data [15]. Zhou et al. introduced a short-term safety monitoring program by means of a risk assessment system. The numerical monitoring data were directly input into the SVM model [16]. Xu designed and developed a dynamic remote sensing monitoring database system and built a massive geospatial database by using GIS and spatial database technology. The platform can provide users with data browsing and query and analysis functions [17]. Santos et al. proposed a method of an automatic life cycle assessment (LCA) within a BIM-based environment. The work presented BIM objects' libraries for data collection and analysis [18]. Shahrour et al. proposed a comprehensive digital solution for the utility tunnel which used advanced monitoring system to collect data about the tunnel. The system was used to collect and analyze monitoring data to improve the utility security and performance [19]. Despite the mathematical convenience to analyze and predict data, the excavation-induced adverse impact on surrounding environment and interaction mechanism should be analyzed with the comprehensive management of excavation information and monitoring data. 
TABLE 1: The difference between proposed system and common risk monitoring systems.

\begin{tabular}{|c|c|c|}
\hline & Common system & Proposed system \\
\hline $\begin{array}{l}\text { Modeling } \\
\text { object }\end{array}$ & $\begin{array}{l}\text { Single foundation pit with series of excavation } \\
\text { stages }\end{array}$ & $\begin{array}{c}\text { Information management of multiple excavation in foundation pit } \\
\text { group }\end{array}$ \\
\hline Resear & $\begin{array}{l}\text { Analysis of stress and deformation characteristics } \\
\text { during excavation from overall foundation pit }\end{array}$ & $\begin{array}{c}\text { Interaction analysis in local time and space due to the superposition } \\
\text { effect of multiple block and partition excavation }\end{array}$ \\
\hline $\begin{array}{l}\text { Data } \\
\text { management }\end{array}$ & $\begin{array}{l}\text { Articulating data directly in traditional Revit model } \\
\text { files }\end{array}$ & $\begin{array}{l}\text { Being more lightweight and compatible through digital-analog } \\
\text { separation }\end{array}$ \\
\hline Data analysis & $\begin{array}{l}\text { Analysis of the monitoring data without the } \\
\text { combination of excavation information }\end{array}$ & $\begin{array}{l}\text { Carrying out the statistical analysis } \\
\text { abstract data in combination with the }\end{array}$ \\
\hline
\end{tabular}

In addition to the information record system and database, a comprehensive management system contributes to behavioral analysis and risk assessment throughout the excavation stage. Sun et al. developed the management information system based on Web GIS for monitoring foundation construction. The system can implement the release, visualization, and real-time alarm warning functions, which is of great significance to construction safety management and risk control [20]. Wu et al. developed a BIM-based monitoring system to integrate and visualize monitoring data for risk assessment during urban deep excavation [21]. Ding et al. developed a visual and information-rich management system by using the building information modeling (BIM) and web technology to establish a risk management framework [22]. Zhu et al. designed and developed the safety monitoring information management system for deep foundation pits and adjacent buildings. The stress and deformation were analyzed comprehensively by combining with monitoring information and measured points arrangement [23]. Providakis et al. presented a newly-developed methodology to utilize 3DBIM-based models for the prediction of the tunneling-induced settlement. The model was also capable for risk estimation of tunnel with BIM data and MATLAB meshing and analysis tools [24].

However, the foundation pit management systems introduced above have following disadvantages. There is a lack of functional integration system which can implement data storage, visualization, coupling analysis, and risk assessment synchronously. Most systems seldom attribute to manage several excavations information and analyze the mutual influence, which will aggravate the excavation-induced adverse impact on surrounding environment in a foundation pit group.

\section{Design of the Digital System}

3.1. Architecture. This digital system adopts $\mathrm{C} / \mathrm{S}$ (client/server) architecture, including the client based on.NET framework and the server based on SQL Server external database. Additionally, the system combines ADO.NET technology, ActiveX technology, and automation technology and integrates the secondary development of Excel and Visio software. The system includes four consecutive modules and they are VSCM, database establishment, visual modeling, and coupling analysis (Figure 1). Through the following four modules, the dynamic and synchronous analysis of foundation pit construction and response is well implemented. The following four sections are conducted to interpret the consecutive modules.

3.2. VSCM. This section puts forward the comprehensive management platform to record construction and monitoring information based on Autodesk Revit software, named as "Visualization System for Foundation Pit Construction Information and Monitoring Data" (VSCM for short). The threedimensional display of excavation process was carried out against elapsed time. Meanwhile, the foundation pit measuring points and monitoring data were stored and dynamically inquired in Revit software. It consists of three modules: excavation, monitoring, and construction information, which are used for excavation information management, monitoring data management, and dynamic query of construction information, respectively. Figure 2 shows the interface of the software developed based on Autodesk Revit.

The soil modeling of foundation pit is divided into initial soil modeling and excavation soil modeling. Both of them are generated and numbered by each soil element; therefore, the excavation process can be displayed by the removal of excavated soil elements. For any soil element, there are four states shown in the model with different forms in Revit software. Meanwhile, the precision recording of excavation information was carried out through smoothing approximation method in Revit, which solved the problem of precision recording during excavation. Finally, the precision recording of excavation information can be used to inquire the excavation process of the entire project dynamically with the combination of time information. Table 2 lists the displayed styles for soil regions in different excavation stages.

The monitoring information includes monitoring items, instruments layout, and field data. In order to facilitate the management of monitoring data, the storage, query, modification, and real-time addition can be achieved by means of Microsoft SQL Server external database. Further, the VSCM provides the corresponding import and export functions of field data from Revit to Excel data sheet.

Generally, VSCM is applied to inquire the full information of complex excavation stages and monitoring data in a foundation pit group, so it is very convenient for decisionmakers to query the current state.

3.3. Database Establishment. A database is the basis of dynamic and synchronous analysis in a foundation pit 


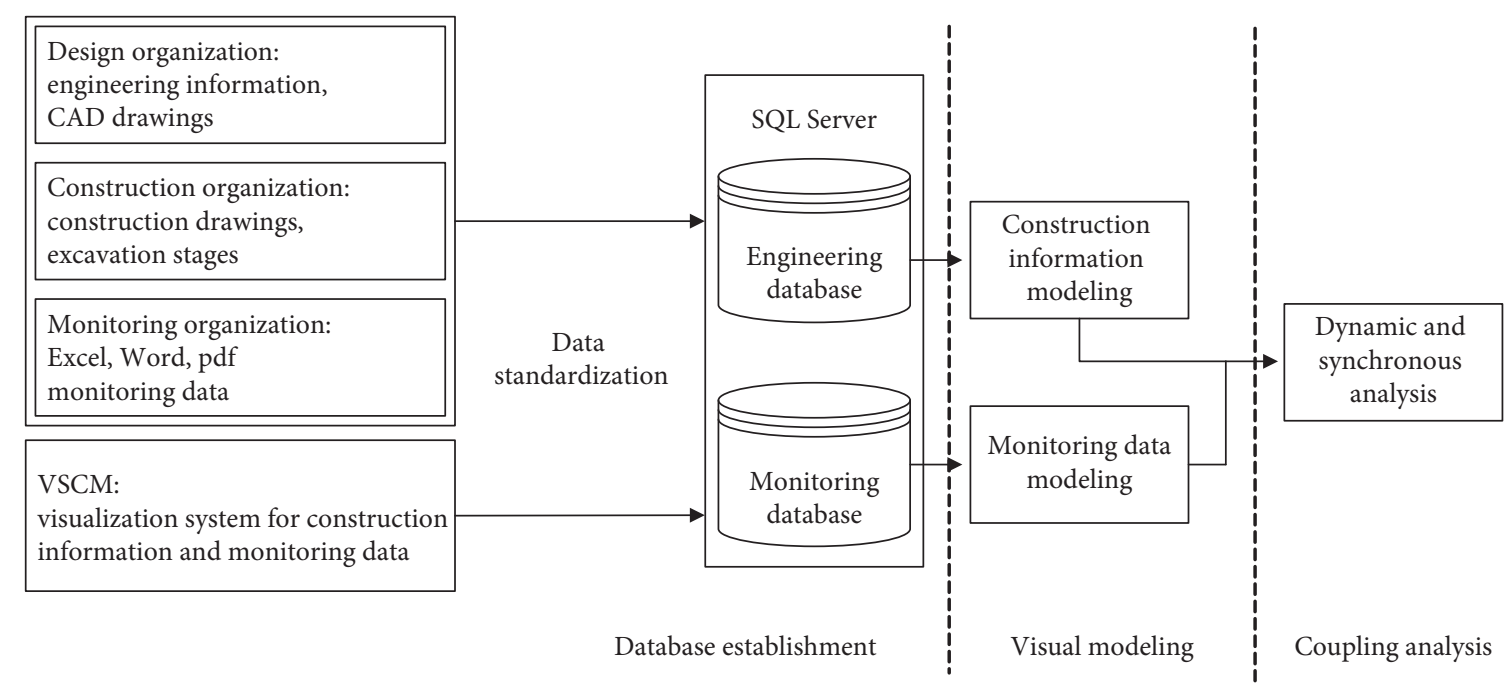

FIGURE 1: Systematic program scheme design.

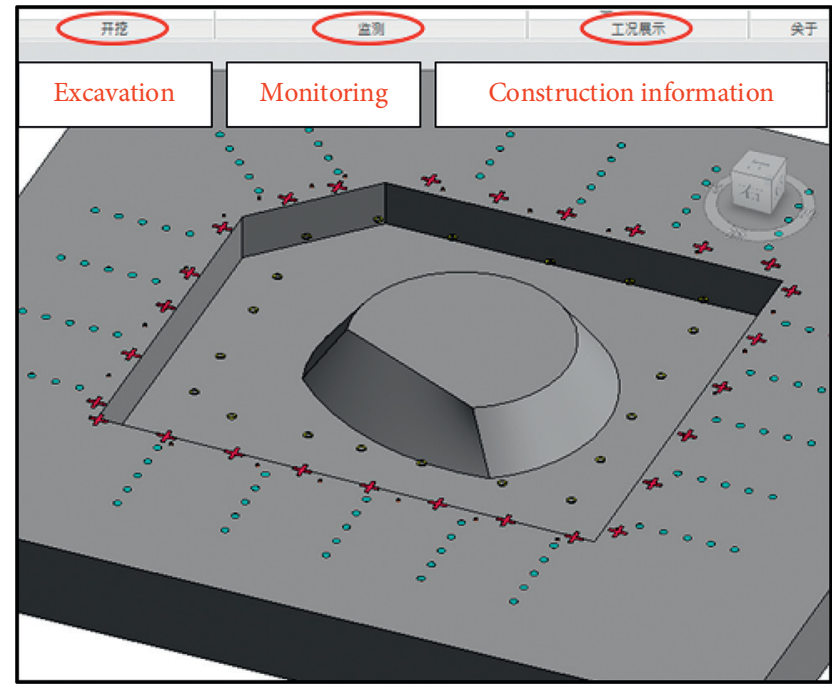

FIgURE 2: User interface of the developed software based on Autodesk Revit.

TABLE 2: Displayed styles for soil regions in different excavation stages.

\begin{tabular}{lc}
\hline Excavation stages & Display style for soil regions in Revit \\
\hline Not excavated & Completely opaque, grey surface \\
Being excavated & $50 \%$ transparency, red surface \\
Completed & Completely transparent \\
Unclear & $30 \%$ transparency, green surface \\
\hline
\end{tabular}

group. The corresponding tools were developed to extract table data in Excel and Word directly, and then the extracted data were converted into standard formats automatically. According to relevant classification and organization principle, the data in the whole foundation pit group are stored in the SQL Server database. The database in the construction process can be divided into engineering information, construction information, and monitoring information. Engineering information refers to the characteristic parameters, such as excavation area, depth, location, and adjacent structures. Construction information refers to the current construction progress, such as the location of block excavation, current excavation depth, and inner support system. Monitoring information refers to the coordinate of measured points and monitoring data, such as the spatial location of inclinometer casings and level instrument.

Revit software is used to record "construction information" and "monitoring data," which are then extracted into SQL Server database. A clear structural relationship between construction information and monitoring data is established (Figure 3). This method provides a convenient approach to inquire and fuse both information according to the time node. The monitoring time, completion time, installation time, and removal time are all critical time nodes, which collectively constitute the benchmark for synchronous analysis during excavation.

3.4. Visual Modeling. Visualization is an essential technology in the management system, which is used to convert excavation stages and monitoring data into images through the developed plug-ins of Visio and Excel software, respectively.

3.4.1. Curve Modeling of Monitoring Data. A large amount of monitoring data which represent the excavation behaviors have been collected. The collected items include wall lateral deflections, wall vertical movements, ground settlements, column vertical movements, and support stresses. It is unavailable to observe the features of monitoring data in the form of numbers or tables. Therefore, data from all monitoring items are extracted to draw corresponding dynamic curves against elapsed time.

However, excavation behaviors are affected by various and complex factors such as soil conditions, excavation methods, support system, and pit geometrics, which makes the massive field data difficult to process. Firstly, the system provides operation interface to draw curves of single 
PK: the primary key in data table, unique identification

FK1, FK2: the foreign keys in data table, association between data

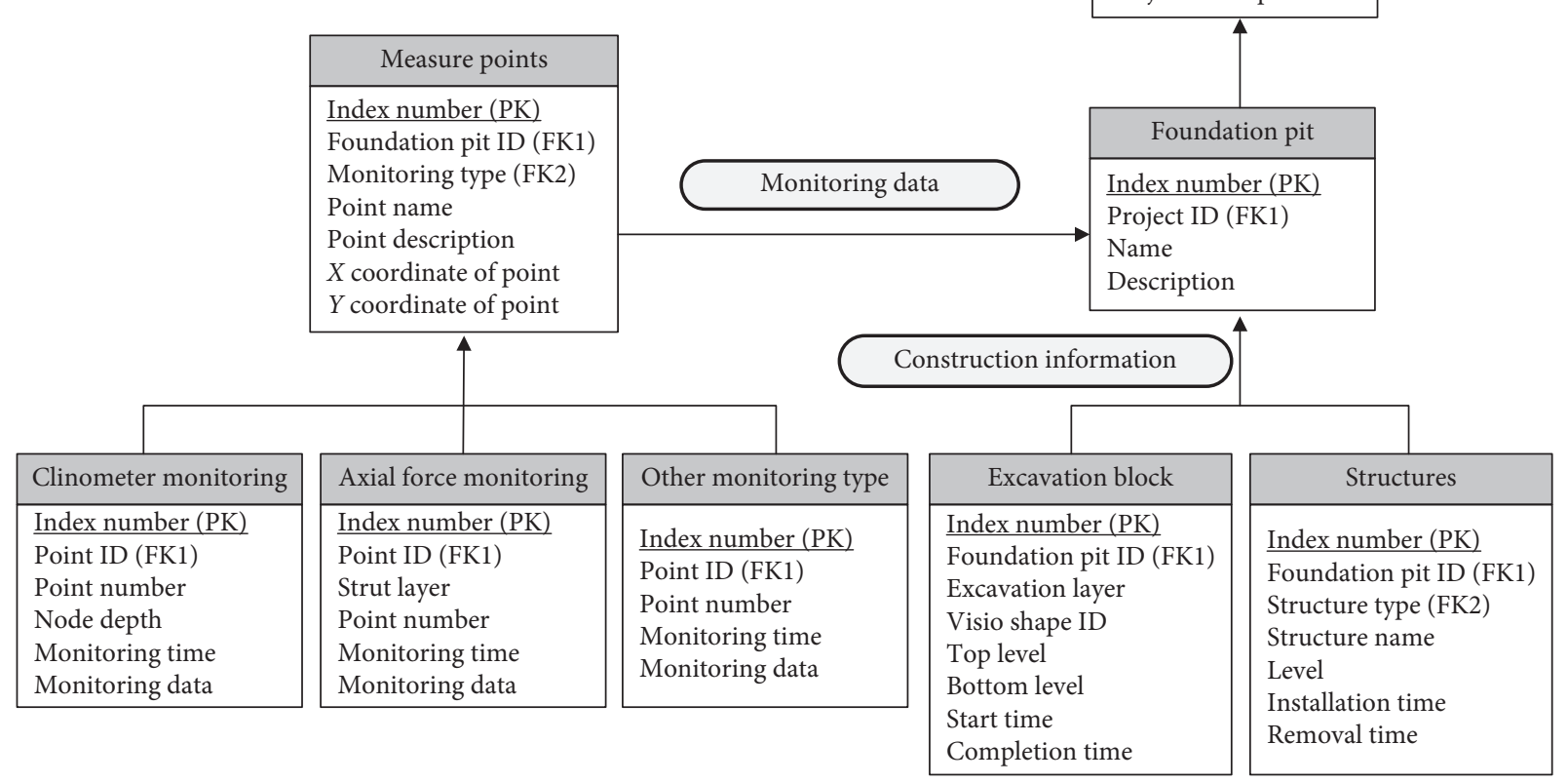

FIgURE 3: Excavation project database relationship diagram.

monitoring item. By investigating the generated curves, the distribution and trends of single excavation behavior are obtained [25-27]. Secondly, many literatures suggested that an experiential relationship existed between behaviors and potential geometric of the foundation pit, called data normalization processing. Several coupling relationships, between (1) the measured maximum wall deflection and excavation depth, (2) the depth where maximum wall deflection occurred and excavation depth, (3) the maximum wall deflection and the corresponding maximum ground settlement, and (4) the steel support stress and compression, are available in correlational studies $[28,29]$. The system is also capable to provide the operation interface to draw curves of multiple monitoring items based on the corresponding relationship.

\subsubsection{State Modeling of Excavation Stages.} Two-dimensional modeling through Visio tool was developed to implement the visualization and dynamic query of each excavation stage. The effects of adjacent excavations on behaviors of foundation pit are currently reflected in local temporal and spatial aspects. Therefore, the state modeling of excavation stages should be refined to the scale of partition and block, which is beneficial to restore the whole dynamic process for subsequent analysis.

In this system, a plug-in was developed on Visio to achieve the conversion from written records and CAD drawings to Visio graphics. The Visio plug-in for visualized simulation of foundation pits block excavation and instrumentations layout is shown in Figure 4.
3.5. Dynamic and Synchronous Analysis. Based on the curve modeling of monitoring data and state modeling of excavation stages, the system was applied for establishing a connection between them with the help of time nodes (see Figure 3). The dynamic and synchronous analysis of monitoring data and construction information was carried out by the multithreading technique under the .NET framework ultimately. In the foundation pit group, construction difficulties and risks occur in typical excavation condition and essential nodes generally. Therefore, it is essential to analyze the deformations of adjacent deep excavations when excavation reaches the bottom level and supporting system is removed.

For example, the lateral deflection of diaphragm walls and ground settlement behind the walls are common coupling relationship in the process of excavation (Figure 5), which includes (1) the global dynamic and synchronous control system and time information, (2) the curve of ground settlement against elapsed time, and (3) the wall lateral deformation curve. Therefore, the wall lateral deflections and ground settlement can be clearly obtained attached to the synchronous change between excavations.

The system has several advantages. It is able to process a variety of monitoring data simultaneously to analyze the interaction between different monitoring items. In addition to the correlation analysis of different types of monitoring data, the system can also accomplish coupling analysis under different spatial distributions from the same type of data, as well as the interaction analysis between partial block excavations of adjacent foundation pits. 


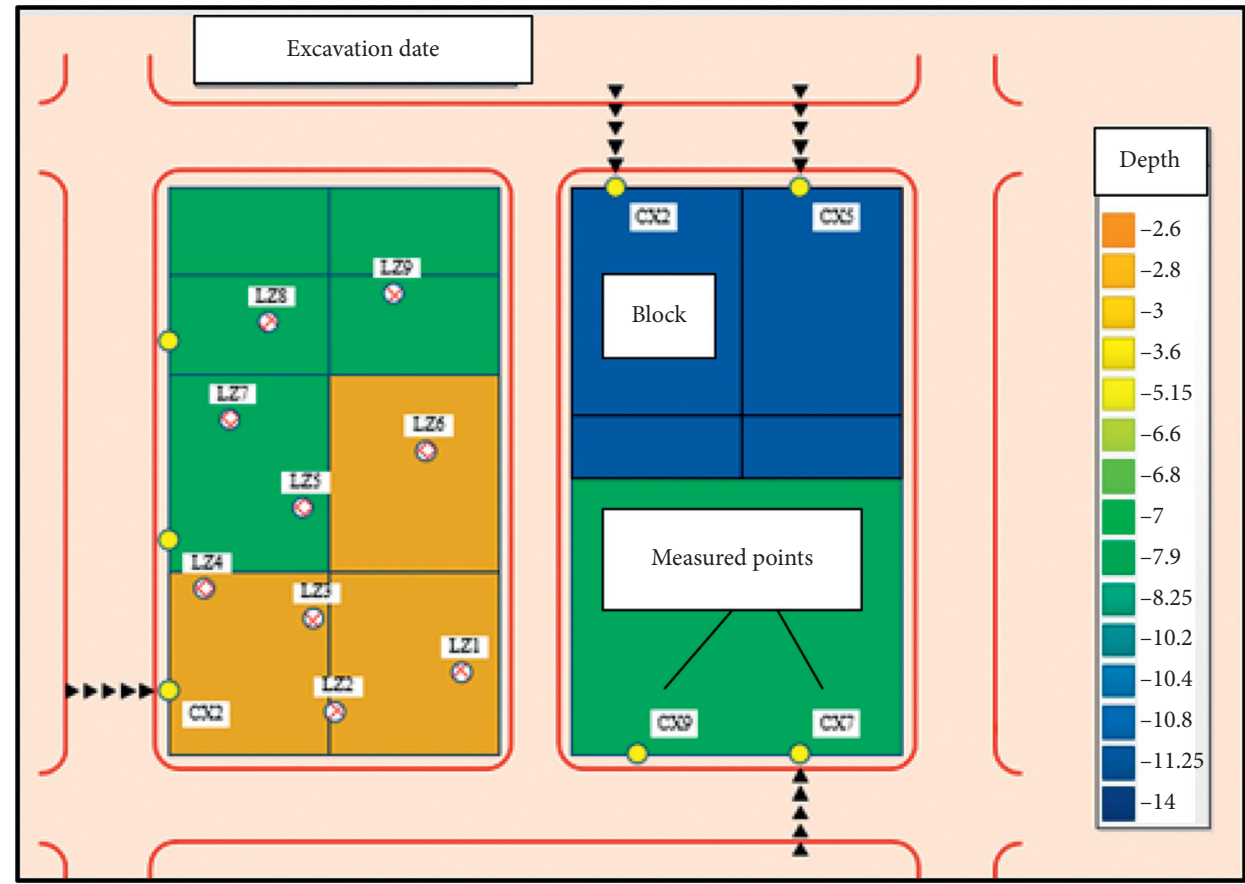

FIgURE 4: Visio plug-in for visualized simulation of excavation and instrumentations layout.

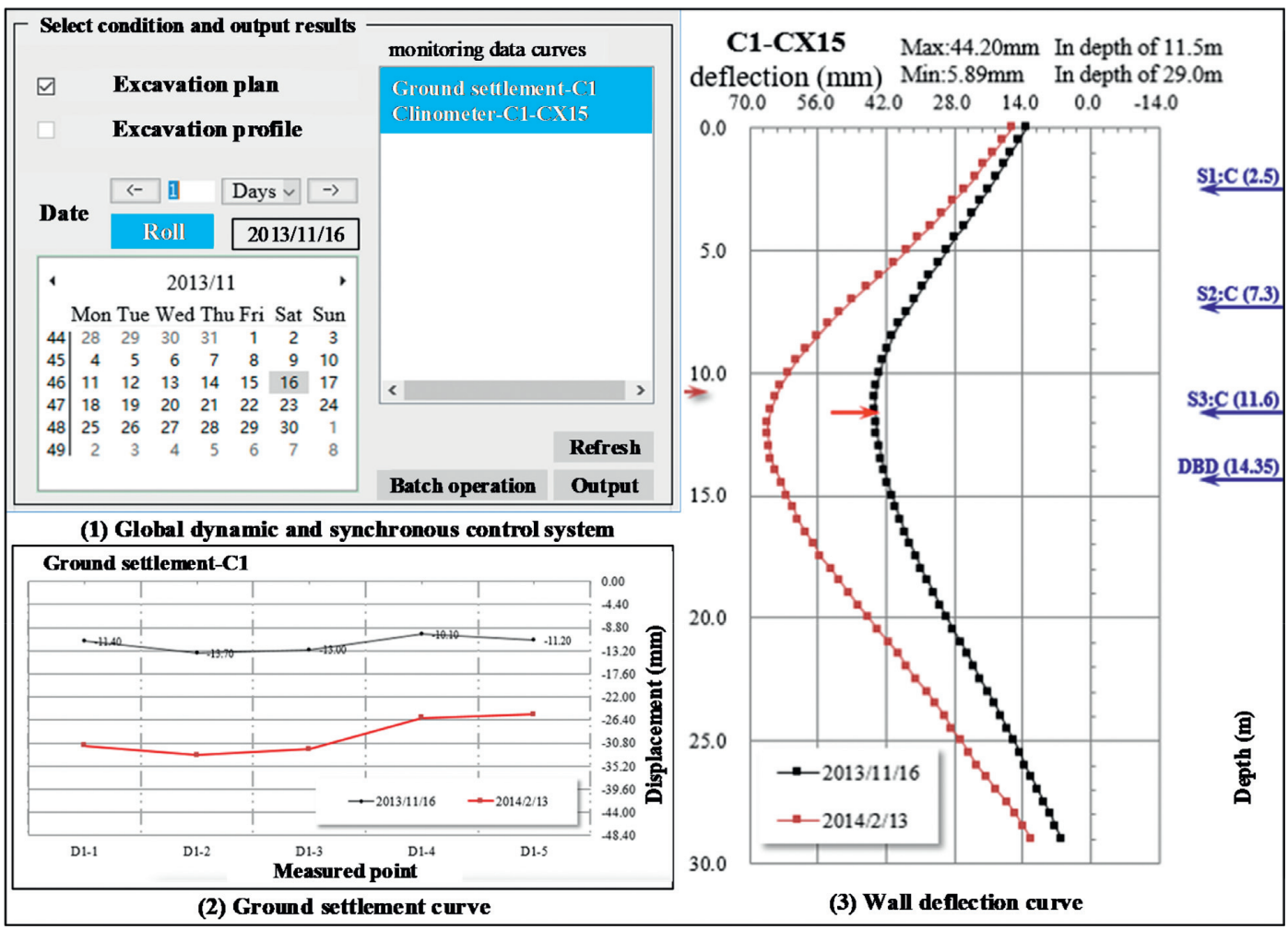

FIgURE 5: Dynamic and coupled analysis of monitoring with excavation stages.

\section{Application for Adjacent Excavation}

4.1. Project Overview. The deep foundation pit project covered an area of approximately $187,200 \mathrm{~m}^{2}$ with a largest excavation depth of $20 \mathrm{~m}$. The foundation pit was divided into six areas: A1, A2, B, C1, C2, and D, which were separated by three roads and formed a large-scale and dense foundation pit group. For the excavation process of foundation pit group, pit A1 was excavated first, and the other pits were excavated simultaneously. In order to implement the refined management of massive construction information and monitoring data, the adjacent foundation pits $\mathrm{C} 1$ 
and D in Shanghai Word Expo Project are taken as the research objects [30]. Then, the deformation behaviors were analyzed during the excavation.

The excavation area of pit $\mathrm{C} 1$ and pit D was $14,361 \mathrm{~m}^{2}$ and $19,320 \mathrm{~m}^{2}$, respectively, and the distance in between was $20 \mathrm{~m}$. Both of them were excavated with the cut-and-cover construction method (Figure 6). Pit $\mathrm{C} 1$ and pit D were excavated in four stages to the elevation of $-11.250 \mathrm{~m}$ and five stages to the elevation of $-14.300 \mathrm{~m}$, respectively. The excavation progress is simplified into four stages and five stages for pit $\mathrm{C} 1$ and pit $\mathrm{D}$, respectively, as shown in Table 3.

The soils excavated in the two foundation pits are mainly typical soft clay with low strength, which may cause large deformation of the retaining structure. Therefore, it is necessary to reinforce the soil within a certain range at the bottom of the foundation pit before excavation to ensure the reasonable and controlled deformation.

4.2. Deformation Monitoring and Layout of Measured Points. In the construction process, the stress and deformation of the foundation pits were monitored, and the main monitoring items included the wall lateral deflections, the ground settlement behind wall, and the displacement at the top of the wall. The wall lateral deflections were monitored by inclinometer instruments with the measured points named CX in pit $\mathrm{C} 1$ and DX in pit D, respectively. The ground settlement behind the walls was monitored by level instruments with the measured points named D1-D6 in global excavation. The displacement at the top of diaphragm walls was monitored by total station instrument with the measured points named CQ in pit $\mathrm{C} 1$ and $\mathrm{DQ}$ in pit $\mathrm{D}$, respectively. The layout of all measured points and corresponding distance are shown in Figure 7.

Wall lateral deflections at middle sides are the focus of this paper. To monitor the deflections of diaphragms in the excavation of pits $\mathrm{C} 1$ and $\mathrm{D}$, inclinometer tubes were tied to the reinforcing cages and at the same depth. Two crosssliding grooves were set in the tubes with one perpendicular to the walls. Meanwhile, the field data of deflections were measured every day during excavation.

4.3. The VSCM Model of Digital System in Excavation Process. Dense measured points were set up on the foundation pit group and surrounding environment to obtain massive field monitoring data in the construction process of Shanghai Word Expo Project. Based on that the three-dimensional information, excavation stages, and measured point arrangement were recorded in Revit through the VSCM system; the dynamic and visual excavation process can be displayed in real time (Figure 8). Therefore, that information recorded in VSCM against elapsed time was exported to SQL Server database by combining with the data conversion interface, and the excavation stages information was synchronously transformed into Visio graph.
4.4. Measured Maximum Lateral Deflection of Adjacent Foundation. As an important monitoring and analysis object in excavation, lateral deflections of diaphragm walls act as an important controlling factor for the safety of foundation pit. This part takes the lateral deflection in pits $\mathrm{C} 1$ and $\mathrm{D}$ as an example to illustrate the interactions in each excavation stage of adjacent foundation pits. There are respectively five (CX5, CX7, CX9, CX13, and CX15) and ten (D1 D3, D6 D8, D16, D18, D21, and D22) typical measured points in the foundation pits $\mathrm{C} 1$ and $\mathrm{D}$ selected in this project for statistical analysis and drawing curves of maximum lateral deflection.

The general variation of the maximum wall lateral deflections at typical measuring points of both pits $\mathrm{C} 1$ and $\mathrm{D}$ against elapsed time is obtained (Figure 9). Generally speaking, the maximum lateral deflection increases with the continuous excavation by marking the excavation stages of the foundation pit. The walls in pit $\mathrm{D}$ tend to be stabilized after excavation to the bottom, while the deflection of pit $\mathrm{C} 1$ continues increasing within a month after the final excavation stage which is caused by removal of the struts. The results show that the adjacent excavation has mutual influence on the wall lateral deflection.

\section{Results and Discussion}

The deformation behavior and environment impact of the foundation pit group at each excavation stage are revealed. The system can present the changes of different types of monitoring data simultaneously (see Figure 5). In order to analyze the variation tendency of monitoring data with excavation stages in a foundation pit group, the system is also used to carry out refined modeling of block excavation. Synchronous analysis consisted of excavation stages model and monitoring data curve is conducted to examine the interactions of adjacent excavations.

It can be found by the monitoring curves of maximum lateral deflection that the wall lateral deflection of the adjacent side is less than that of the far side. Locally, the curve of clinometer CX5 shows a "downward convex shape" in the third layer soil excavation, indicating that the wall bounces outward. The special phenomenon illustrates the locally unbalanced soil pressure on both sides of the adjacent foundation with the unloading effect of excavation, which causes the local and outward movement of the diaphragm wall.

In order to revel the rebound phenomenon of the diaphragm wall, the partitioned excavation is meticulously modelled in the foundation pit group. The dynamic synchronous playback is conducted by comparing the excavation stages and monitoring the curve in visualization model (Figure 10). The measured point and the freshly excavated soil are represented by red dot and red star, respectively. It can be quickly found that local excavation will 


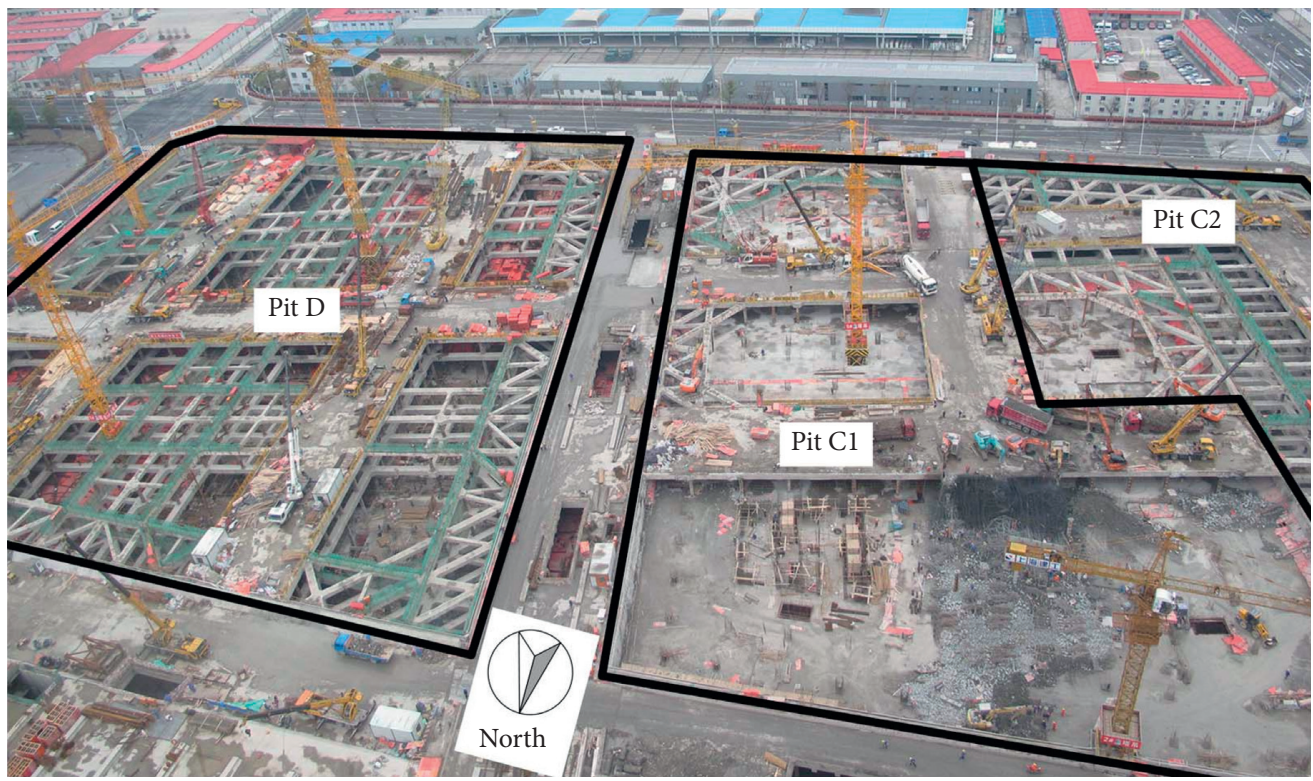

Figure 6: Photo of the construction fields of pits C1 and D at Shanghai expo.

TABLE 3: Simplified construction schedule for pits C1 and D.

\begin{tabular}{lccc}
\hline & Step & Condition & Depth (m) \\
\hline & 1 & Surface soil removal & 0.5 \\
Pit $C 1$ & 2 & First floor excavation and strut installation & 4.7 \\
& 3 & Second floor excavation and strut installation & 4.3 \\
& 4 & Third floor excavation and strut installation & 4.35 \\
& 1 & Surface soil removal & 0.5 \\
\hline & 2 & Surface soil removal & 0.5 \\
Pit $D$ & 3 & First floor excavation and strut installation & 4.1 \\
& 4 & Second floor excavation and strut installation & 4.0 \\
& 5 & Fourth floor excavation and strut installation & 4.8 \\
\hline
\end{tabular}

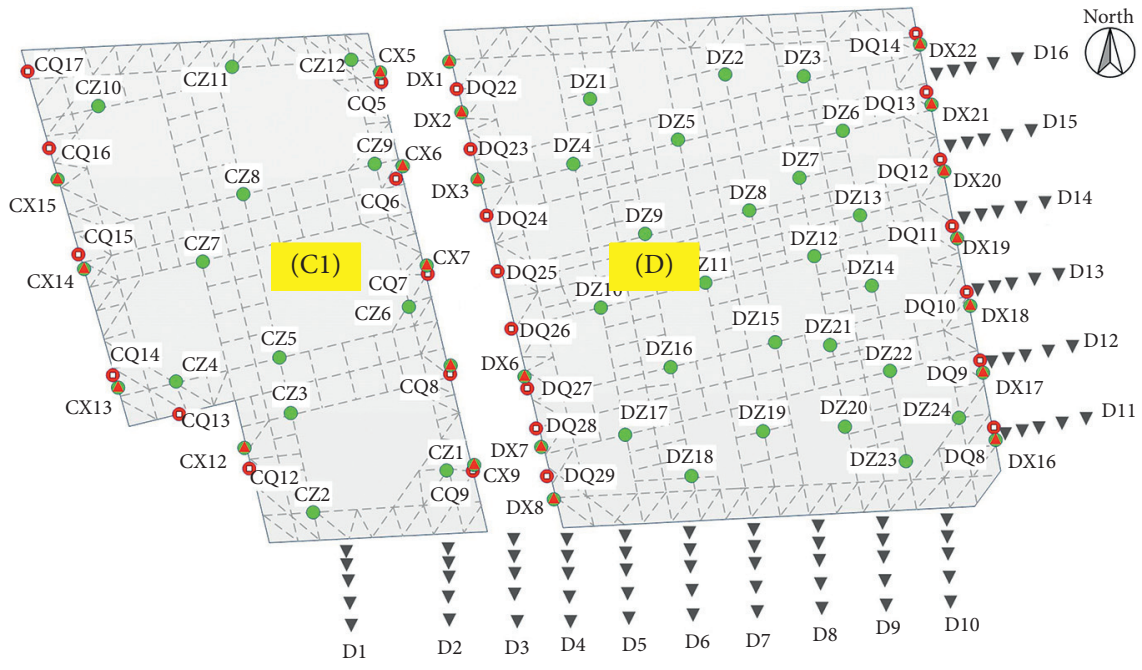

FIGURE 7: Layout of measured points and corresponding distance. 


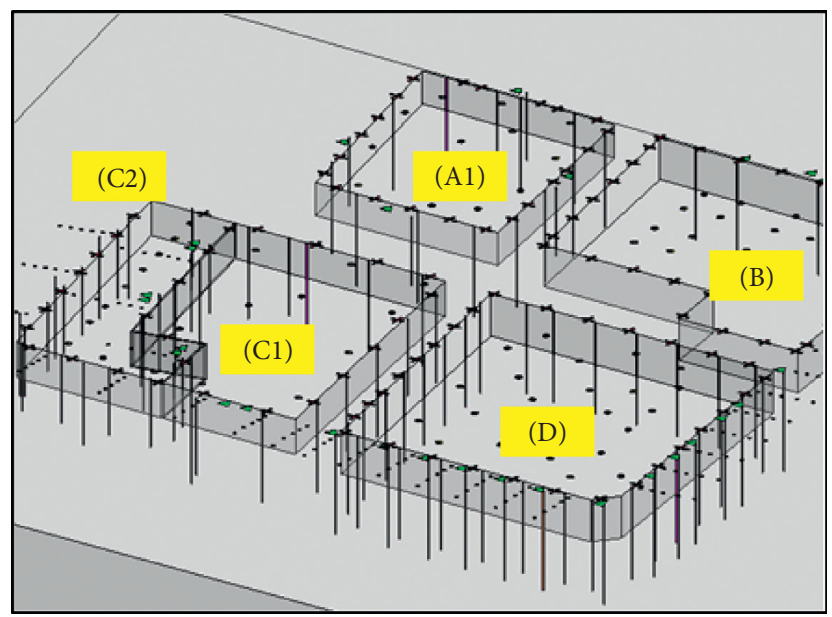

Figure 8: Recording of instrumentations arrangement of the Expo Project with Revit.

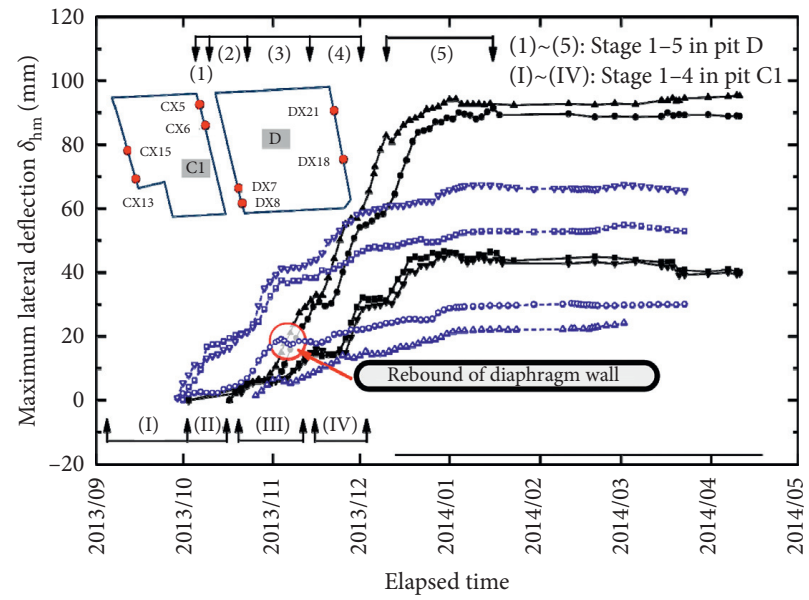

$$
\begin{array}{llll}
\text { C1-WEST } & \text { C1-EAST } & \text { D-WEST } & \text { D-EAST } \\
-\backsim \text { CX13 } & -- \text { CX5 } & \rightarrow \text { DX7 } & \rightarrow \text { DX18 } \\
-\rightarrow \text { CX15 } & -\rightarrow \text { CX6 } & \rightarrow \text { DX8 } & \rightarrow \text { DX21 }
\end{array}
$$

Figure 9: Measured maximum lateral deflections of adjacent foundation in both pits C1 and D.

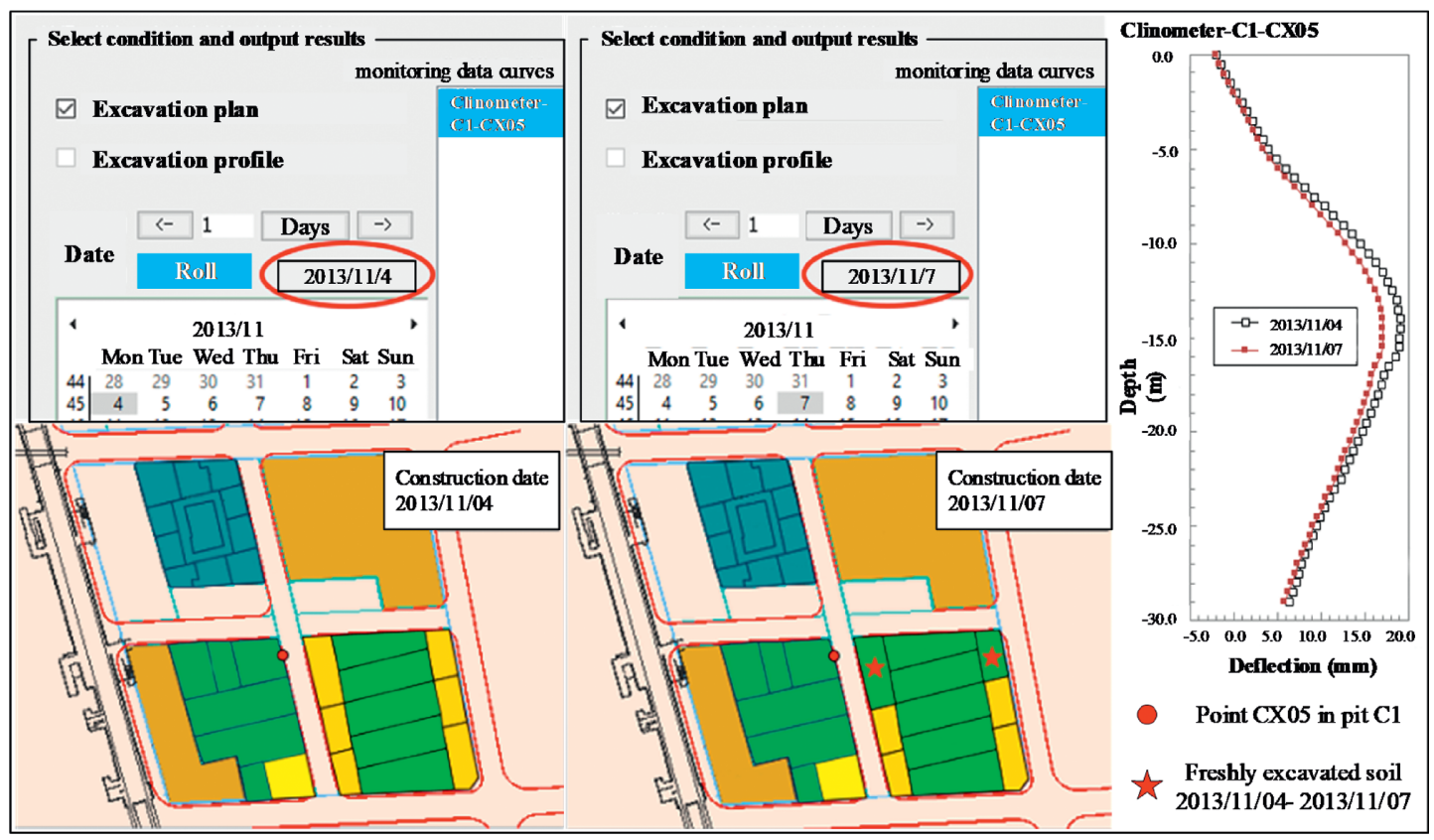

Figure 10: Synchronous changes of the excavation stage and the wall deflection profile. 
lead to local imbalance of soil pressure on both sides of the adjacent foundation pit. Therefore, the unloading effect can cause local movement of wall to the outside of the pit.

\section{Conclusions}

In this paper, a digital system for the foundation pit group has been developed that enabled information record, database establishment, and visual modeling during adjacent deep excavations. The system was applied to a foundation pit group of Shanghai World Expo Project to manage construction information and monitoring data. With the developed system, the performance and interactions of foundation pits were analyzed.

The VSCM for construction information and monitoring data was proposed based on Revit software which consists of three modules: excavation, monitoring, and construction information. The system can record and manage the three-dimensional geometry information and excavation stages of foundation pit against elapsed time to facilitate the dynamic query of the entire construction process.

As a functional integration system, the digital system for dynamic and synchronous analysis was developed through SQL Server database with standardization management function. Meanwhile, it was developed through secondary development of Visio and Excel tools with visualization and curve modeling function. In terms of application, the digital system was applied to the several adjacent excavations of Shanghai World Expo Project which revealed the variation of wall lateral deflections. The efficient analysis method is capable to investigate abnormal performance and analyze the interactions with surrounding environment efficiently, which is of great benefit for similar projects to provide guidance.

In the whole analysis process, the massive monitoring data were integrated and correlated in the form of dynamic visualization. With the developed system, correlations between different types of monitoring data and excavation stages can be mined more efficiently.

\section{Data Availability}

The data used to support the findings of this study are available from the corresponding author upon request.

\section{Conflicts of Interest}

The authors declare no conflicts of interest.

\section{Acknowledgments}

The authors thank the study participants and teachers for their cooperation and support. This research was substantially supported by the National Natural Science Foundation of China (Grant nos. 41727802 and 41977216) and by the Shanghai Rising-Star Program (Grant no. 19QC1400800); the authors thank them for their financial support.

\section{References}

[1] J.-J. Chen, Y.-F. Zhu, M.-G. Li, and S.-L. Wen, "Novel excavation and construction method of an underground highway tunnel above operating metro tunnels," Journal of Aerospace Engineering, vol. 28, no. 6, p. A4014003, 2015.

[2] L. Shi, W. Yu, and L. Fu, "Deformation analysis of deep foundation pit in soft soil area considering space-time effect," The Journal of Engineering, vol. 2019, no. 11, pp. 8274-8281, 2019.

[3] X. Li and H. Zhu, "Development of a web-based information system for shield tunnel construction projects," Tunnelling and Underground Space Technology, vol. 37, pp. 146-156, 2013.

[4] A. Akanmu, O. Olatunji, P. E. D. Love, D. Nguyen, and J. Matthews, "Auto-generated site layout: an integrated approach to real-time sensing of temporary facilities in infrastructure projects," Structure and Infrastructure Engineering, vol. 12, no. 10, pp. 1243-1255, 2016.

[5] D.-G. Lee, J.-Y. Park, and S.-H. Song, "BIM-based construction information management framework for site information management," Advances in Civil Engineering, vol. 2018, Article ID 5249548, 14 pages, 2018.

[6] F. Rodrigues, J. Teixeira, R. Matos, and H. Rodrigues, "Development of a web application for historical building management through BIM technology," Advances in Civil Engineering, vol. 2019, Article ID 9872736, 15 pages, 2019.

[7] P.-C. Lee, L.-L. Zheng, T.-P. Lo, and D.-B. Long, "A risk management system for deep excavation based on BIM3DGIS framework and optimized grey Verhulst model," KSCE Journal of Civil Engineering, vol. 24, no. 3, pp. 715-726, 2020.

[8] Y. M. A. Hashash, C. Marulanda, J. Ghaboussi, and S. Jung, "Novel approach to integration of numerical modeling and field observations for deep excavations," Journal of Geotechnical and Geoenvironmental Engineering, vol. 132, no. 8, pp. 1019-1031, 2006.

[9] Y. Y. Su, Y. M. A. Hashash, and L. Y. Liu, "Integration of construction as-built data via laser scanning with geotechnical monitoring of urban excavation," Journal of Construction Engineering and Management, vol. 132, no. 12, pp. 1234-1241, 2006.

[10] S. Fekete, M. Diederichs, and M. Lato, "Geotechnical and operational applications for 3-dimensional laser scanning in drill and blast tunnels," Tunnelling and Underground Space Technology, vol. 25, no. 5, pp. 614-628, 2010.

[11] C. Kim, B. Kim, and H. Kim, "4D CAD model updating using image processing-based construction progress monitoring," Automation in Construction, vol. 35, pp. 44-52, 2013.

[12] T. Omar and M. L. Nehdi, "Data acquisition technologies for construction progress tracking," Automation in Construction, vol. 70, pp. 143-155, 2016.

[13] L. S. Kang, H. S. Kim, H. S. Moon, and S.-K. Kim, "Managing construction schedule by telepresence: integration of site video feed with an active $\mathrm{nD}$ CAD simulation," Automation in Construction, vol. 68, pp. 32-43, 2016.

[14] Y. Sang, J. Zhao, F. Duan, W. Sun, and H. Zhao, "A novel automatic device to measure deformation inside transparent soil based on digital image correlation technology," Measurement Science and Technology, vol. 30, no. 3, p. 035202, 2019.

[15] C. Y. Kim, G. J. Bae, S. W. Hong, C. H. Park, H. K. Moon, and H. S. Shin, "Neural network based prediction of ground surface settlements due to tunnelling," Computers and Geotechnics, vol. 28, no. 6-7, pp. 517-547, 2001. 
[16] Y. Zhou, W. Su, L. Ding, H. Luo, and P. E. D. Love, "Predicting safety risks in deep foundation pits in subway infrastructure projects: support vector machine approach," Journal of Computing in Civil Engineering, vol. 31, Article ID 04017052, 2017.

[17] Z. Xu, "Dynamic monitoring and management system for land resource based on parallel network algorithm and remote sensing," Journal of Intelligent \& Fuzzy Systems, vol. 37, no. 1, pp. 249-262, 2019.

[18] R. Santos, A. A. Costa, J. D. Silvestre, T. Vandenbergh, and L. Pyl, "BIM-based life cycle assessment and life cycle costing of an office building in Western Europe," Building and Environment, vol. 169, 2020.

[19] I. Shahrour, H. Bian, X. Xie, and Z. Zhang, "Use of smart technology to improve management of utility tunnels," Applied Sciences, vol. 10, no. 2, p. 711, 2020.

[20] Y. F. Sun and M. Ding, "Development of management information system based on web GIS for monitoring of pipejacking engineering," Applied Mechanics and Materials, vol. 743, pp. 667-672, 2015.

[21] I. Wu, S. Lu, and B. Hsiung, "A BIM-based monitoring system for urban deep excavation projects," Visualization in Engineering, vol. 3, pp. 1-11, 2015.

[22] L. Y. Ding, B. T. Zhong, S. Wu, and H. B. Luo, "Construction risk knowledge management in BIM using ontology and semantic web technology," Safety Science, vol. 87, pp. 202213, 2016.

[23] C. Zhu, Z. Yan, Y. Lin, F. Xiong, and Z. Tao, "Design and application of a monitoring system for a deep railway foundation pit project," IEEE Access, vol. 7, pp. 107591107601, 2019.

[24] S. Providakis, C. D. F. Rogers, and D. N. Chapman, "Predictions of settlement risk induced by tunnelling using BIM and 3D visualization tools," Tunnelling and Underground Space Technology, vol. 92, Article ID 103049, 2019.

[25] Y. M. A. Hashash, S. Levasseur, A. Osouli, R. Finno, and Y. Malecot, "Comparison of two inverse analysis techniques for learning deep excavation response," Computers and Geotechnics, vol. 37, no. 3, pp. 323-333, 2010.

[26] Y. Liu, B. Xiang, and M. Fu, "Observed performance of a large-scale deep triangular excavation in Shanghai soft clays," Geotechnical and Geological Engineering, vol. 37, no. 4, pp. 2791-2809, 2019.

[27] X. Gao, W.-p. Tian, and Z. Zhang, "Analysis of deformation characteristics of foundation-pit excavation and circular wall," Sustainability, vol. 12, no. 8, p. 3164, 2020.

[28] Y. Tan and D. Wang, "Characteristics of a large-scale deep foundation pit excavated by the central-island technique in Shanghai soft clay. I: bottom-up construction of the central cylindrical shaft," Journal of Geotechnical and Geoenvironmental Engineering, vol. 139, no. 11, pp. 1875-1893, 2013.

[29] G. Liu, J. Guo, M. Li, T. Qin, and P. Huang, "Measured behaviors of an oversized irregular basement excavation and its surrounding responses in thick soft clay," Arabian Journal Geoscience, vol. 13, 2020.

[30] F. Y. Zeng, Z. J. Zhang, J. H. Wang, and M. G. Li, “Observed performance of two adjacent and concurrently excavated deep foundation pits in soft clay," Journal of Performance of Constructed Facilities, vol. 32, Article ID 04018040, 2018. 